\title{
EFFECTIVENESS OF AUDIO-VISUAL AIDS IN TEACHING LOWER SECONDARY SCIENCE IN A RURAL SECONDARY SCHOOL
}

\author{
Daniel Tang Kuok Ho ${ }^{1 *}$ and Rangis Intai ${ }^{2}$ \\ ${ }^{1}$ Curtin University Sarawak, CDT 250, 98009 Miri, Sarawak, Malaysia \\ ${ }^{2}$ Sekolah Menengah Kebangsaan Subis, Batu Niah, Miri, Sarawak, Malaysia \\ *Corrresponding author: daniel.tang@curtin.edu.my
}

Published date: 10 August 2018

To cite this article: Tang D. K. H., \& Intai, R. (2017). Effectiveness of audio-visual aids in teaching lower secondary science in a rural secondary school. Asia Pacific Journal of Educators and Education, 32, 91-106. https://doi.org/10.21315/apjee2017.32.7

To link to this article: https://doi.org/10.21315/apjee2017.32.7

\begin{abstract}
The study investigates the effectiveness of audio-visual aids in teaching the topic of reproduction, a lower secondary science topic, in a rural secondary school in Miri, Sarawak. The study is a quasi-experiment with questionnaire survey to provide insight into perception of the experimental group on audio-visual aids. Study participants consisted of 30 Form 3 students of evenly distributed academic performance, with 15 in control group and 15 in experimental group. Students in control group were taught using chalk and talk method while students in experimental group were taught using audio-visual aids. Pre- and post-assessments were administered to the students in both group to monitor how the two teaching approaches affected students' test results. A survey was conducted among students in experimental group to gauge their perceptions towards the use of audiovisual aids in teaching. The pre- and post-assessment results were analysed with ANOVA while the survey findings were analysed with Pearson correlation. SPSS was used for the statistical analyses. The study shows that audio-visual aids are effective in increasing the understanding of students as indicated in the significantly improved marks for postassessment in the experimental group. Students were observed to be more attentive when audio-visual aids were played. Majority of students in the experimental group agreed that the use of audio-visual aids increased their interest and ability to remember the contents. The students in general expressed that they were motivated to learn if audio-visual aids were incorporated in the teaching and learning process. This study contributes to teaching of lower secondary science in rural schools by suggesting that teachers in rural secondary schools could download the audio-visual aids prior to using them in lesson delivery and the
\end{abstract}


aids should undergo review to ensure appropriateness. In rural schools, financial allocation and maintenance of portable hardware for display of the audio-visual aids in teaching and learning should be looked into for the betterment of teaching and learning.

Keywords: audio-visual aids, effectiveness, lower secondary, science, rural

\section{INTRODUCTION}

Advancement of technology has given new dimensions to teaching and learning. It expands teaching and learning beyond classrooms and the conventional chalk and talk method. The use of audio-visual aids in teaching and learning has a long history. Audio-visual aids are materials with both audio and visual presentation to support teaching and learning particularly in improving comprehension and retention (Ashaver \& Igyuve, 2013). Prior to the age of radio and television, early audio-visual aids came in the forms of drawings and pictures with oral narrations (DeBernardes \& Olsen, 1948).

The emergence of radio and television transformed the way audio-visual aids were presented by enabling transmission of learning resources to reach audience in wider geographical regions. Audio-visual aids in the forms of radio broadcast and television programs broke through geographical constraints and, coupled with recording devices, enabled educational programs to be recorded, stored and replicated for trainings and educational uses (DeBernardes \& Olsen, 1948). Educational cassettes and video tapes could be used repeatedly for a particular topic. However, audio-visual quality of magnetic tape recording deteriorates over time and upon repetitive replication. Sophistication in recording technology subsequently enables improved preservation of the quality of audio-visual recordings (Keene, 2006).

The early audio-visual aids were generally devoid of interactive capability. Invention of computer introduced animation to audio-visual aids which prior to this, depended on video recording of real-life scenes with narrations and program hosting (Aggarwal, 2009). Animation enables objects at microscopic and particle levels such as bacteria, virus, atoms and molecules to be graphically presented. This revolutionizes teaching and learning by enabling abstract ideas and intangible objects to be vividly demonstrated to learners (Akram, Sufiana, \& Malik, 2012). Computer programs for educational purposes provide interactivity to enhance learning experience. This marks the era where audio-visual aids are connected to multimedia. Audio-visual aids assume more diverse presentations by combining pictures, animations, videos, words, sounds and interactions (Mishra \& Yadav, 2004). 
The age of internet confers greater interactivity, connectivity and flexibility to the creation, dissemination and use of audio-visual aids. Now, people in any part of the world can create videos, animations and podcasts about any educational topics to be shared with anyone who is connected via the World Wide Web. Online platforms such as YouTube and Facebook facilitate sharing of the resources and interaction via comments and live chats. It is apparent at this juncture that sophistication of teaching and learning aids is closely knitted with technology advancement (Ranasinghe \& Leisher, 2009).

Video sharing platforms and social media, with computer technology, catalyse the emergence of audio-visual learning aids. It, now, becomes a common practice for teachers to use audio-visual aids in delivery of various subjects and many studies have been carried out to investigate the usefulness of audio-visual aids in teaching and learning particularly in the teaching of English as Second Language (Keene, 2006; Mathew \& Alidmat, 2013; Mishra \& Yadav, 2004; Oyesola, 2014). A common problem that was pointed out in numerous studies is the selection of appropriate audio-visual aids in light of the multitude of audio-visual aids available. This is because there seems to be an overuse of audio-visual aids since they are readily available and not all audio-visual aids deliver the outcomes expected (Awasthi, 2014; Capper, 2003; Mathew \& Alidmat, 2013).

While it is well established that appropriate audio-visual learning aids optimize learning experiences by providing sensory stimulations (Rao \& Jyoti, 2012), it is unclear how the aids can be practically used in rural secondary schools in Malaysia to teach lower secondary science. The rural secondary schools in Malaysia are generally faced with problems of insufficient technological resources to support adequate use of audio-visual aids in routine teaching and learning. Teaching in these schools are still heavily reliant on the chalk and talk model, aided by pictures. Though much emphasis is placed on student-centered learning, teaching and learning in these schools are inclined to being teacher-centred where a significant amount of time is devoted to teachers explaining and narrating learning contents (Pandian \& Baboo, 2011).

Nonetheless, it is obvious that teacher-centred approach is constrained in many ways when it comes to delivering abstract concepts and narrating intangible objects. Also, teachers invariably find it awkward to narrate intimate body parts and processes in the delivery of topics related to reproduction (Akram et al., 2012). The authors reflected that this lower secondary topic is delivered primarily via explanation and discussion aided by textbook and pictures. It was observed that some students expressed awkwardness in open discussion of the topic and as a result, did not participate in the discussion. The authors also reflected that students 
had difficulty understanding the contents even though explanation was given. This was partly because students could not visualise the processes at cellular level. The authors are of the opinion that it is important for the students to develop adequate understanding of this topic as it is an important topic in the lower secondary science and it is highly probable for questions related to this topic to appear in major assessments.

In this regards, this study aims to identify whether the use of audio-visual aids is effective in the delivery of the topic of reproduction in lower secondary science in a rural secondary school and to gauge the perception of the students in the use of audio-visual aids in their learning. Subsequently, it aims to provide a preliminary framework to optimise the use of audio-visual aids in the teaching and learning of lower secondary science in rural secondary schools.

\section{LITERATURE REVIEW}

The use of audio-visual aids in teaching has been promulgated in a number of studies (Jarosievitz, 2011; Zheng, Warschauer, Lin, \& Chang, 2016; De Sousa, Richter, \& Nel, 2017) as useful tools to convey complicated concepts and ideas in an interesting and interactive manner as well as to facilitate procedural demonstration. Shah and Khan (2015) highlighted that animation and information presented onscreen provided a different learning experience from printed text which was beneficial to development of critical thinking. Gilakjani (2012) also resonated with the use of effective learning materials including audio-visual aids in enhancing teaching and learning, and visual presentation helped differentiating primary and secondary information sources in approaching questions requiring higher thinking skill.

Flipped classroom, being a blended learning mode incorporating online lectures, discussions and audio-visual materials, has been found to encourage reading and watching of visual learning materials among students (Jarosievitz, 2015). Students reflected that they were more engaged in such learning mode. Malik and Agarwal (2012) recognised multimedia as a constructivist learning realm, permitting students to explore and engage in their learning. Audio-visual aids have been applied in multiple teaching and learning settings with encouraging results. Lee and Keckley (2006) revealed higher performance among learners taught via multimedia instruction in driving lessons. De Sousa and Van Eeden (2009) recommended the use of audio-visual materials in teaching history to enhance deep understanding and active learning. Similarly audio-visual aids were reported to be beneficial to the learning of Geography as they vividly presented trends, maps and activities 
(Ekinci, Karakoc, Hut, \& Avci, 2009). For the same reason, audio-visual aids were also advocated for the teaching of social science, for instance among pre-service teacher (De Sousa et al., 2017).

Audio-visual aids are not new to the teaching of science. Ismail, Othman, Amiruddin and Ariffin (2017) used animated video in the delivery of Engineering Drawing among students in a Vocational College of Malaysia and found significant potential of the aids to enhance visualisation of students, hence the quality of learning. Haque and Talukder (2017) having investigated the use of audio-visual aids among undergraduate medical courses in Bangladesh, revealed preference of PowerPoint slides presentation over overhead projector and the importance of good quality audio-visual aids for effective learning. The recent studies are mainly survey-based where empirical attempts to proof effectiveness of audio-visual aids in learning are minimal. Also, studies on application of multimedia and audiovisual aids on teaching language seemed to garner more attention than those on teaching of science (Khan, Shah, Farid, \& Shah, 2016).

While the education system in Malaysia evolves with the advancement in audiovisual and internet technology (Ismail et al., 2017), the research in this area in the recent years has been scarce especially in the rural setting. It was mentioned in the previous section that teachers frequently faced challenges such as inadequate resources and poor internet connectivity while attempting to incorporate audiovisual materials in teaching. It is instrumental to examine how audio-visual aids impact learning among students in rural schools, the limitations encountered in incorporating the materials and how they can be overcome to raise the quality of teaching and learning in rural schools, thus narrowing the gap between students' performance in urban and rural schools.

It has been pointed out that audio-visual aids are beneficial to learning due to the audio-visual processing channels of human mind which register pictures, words and sounds in the sensory memory. This is elicited via the cognitive model of multimedia learning proposed by Mayer (2001) (see Figure 1). Based on the model, pictures and texts entering the eyes and ears are held in the visual and auditory modalities of the short-term memory. Mental conversion between the verbal and pictorial models is possible. The cognitive model culminates at integration which brings the verbal and pictorial models together with prior knowledge in the longterm memory, as learning consolidates (Mayer, 2002). Given the right conditions, students in rural schools can realise greater potential in their learning. 


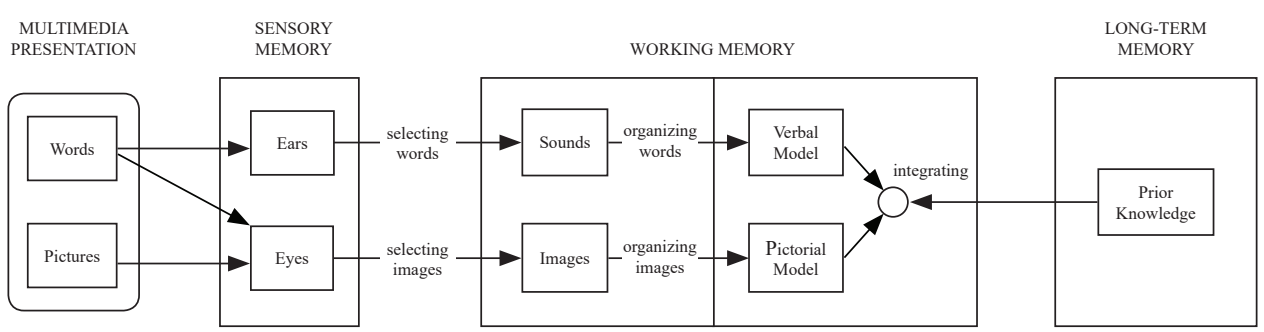

Figure 1. The cognitive theory of multimedia learning (Mayer, 2001)

\section{METHODOLOGY}

The study was carried among 30 Form 3 students from a rural secondary school in Miri, Sarawak. The students were divided into two groups of 15 students respectively. The rationale of the students' segregation was to ensure both groups are as similar as possible in terms of students' academic performance, hence cognitive ability. The students' cognitive ability was determined from the previous science test scores of the students. From previous test scores, the students were divided into high, average and low-performing segments and were equally distributed to each study group (Rao \& Jyoti, 2012; Oyesola, 2014). One group served as the control group and another as the experimental group.

Pre-and post-assessments testing on the topic of reproduction in the lower secondary science syllabus were designed with reference made to the format of PT3 examinations, i.e. a public lower secondary examination. The assessments comprised multiple-choice and short-answer questions of equal mark allocations. The assessments were examined by another lower secondary science teacher and approved by the curriculum officer in fulfillment of administrative and validation procedure. Examination of the assessments included the aspects of relevance, format and taxonomy domains of the questions.

Pre-assessment was given to students in both groups to ascertain their level of understanding on the topic of reproduction. This is to make sure the level of understanding on the topic is similar between students in both groups. The test papers were not returned to the students and not discussed in class. The test paper consists of 10 objective questions and 2 structural questions, each with 5 sub-parts. Construct of the assessment based on the Bloom Taxonomy are shown in Table 1. The assessment excluded test items for synthesizing and evaluating as these two domains have lower weightage of emphasis in lower secondary science. 1 mark was allocated for each objective question and 2 marks for each sub-part of the structural questions. The test has a total of 30 marks. 
Table 1. Construct of assessment in relation to the Bloom taxonomy

\begin{tabular}{lc}
\hline Domain of the Bloom taxonomy & Number of questions \\
\hline Remembering & 6 \\
Understanding & 8 \\
Applying & 4 \\
Analysing & 2 \\
Synthesizing & 0 \\
Evaluating & 0 \\
\hline Total & 20 \\
\hline
\end{tabular}

Students in the control group were taught of the topic using conventional method consisting of diagrams and textbook. Students in the experimental group were taught using audio-visual aids. The audio-visual aids consisted of chosen videos downloaded from the internet. The videos had been reviewed by senior curricular assistant and other lower secondary science teachers and were deemed appropriate to be used as teaching aids due to the clarity of visual presentation and narration. The contents of the videos were agreed by the reviewers to be non-offensive.

The experimental duration spanned over five learning sessions during which the same sub-topics had been covered in both the control and the experimental groups. Unlike the control group, videos related to the sub-topics were played in the experimental group, coupled with explanation to reinforce understanding of students. After five learning sessions, students in both groups were given postassessment. Questions of post-assessment were similar to those in pre-assessment with the sequence of questions changed and some questions testing similar concepts rephrased and modified. Observation was made during the experimental sessions on the response of students to the teaching in both the control and the experimental groups (Mishra \& Yadav, 2004). The marked test papers were kept as record of this study and were not returned to the students.

At the close of the experimental period, students in experimental group were given a questionnaire survey concerning their perception towards the use of audio-visual aids in the learning of science (Rao \& Jyoti, 2012). The questionnaire comprised survey items which investigate whether students find audio-visual aids interesting and effective in helping them understand the topic of reproduction. Items to probe the usefulness of audio-visual aids in the teaching of Science were also included. There were 6 survey items. The survey items were selected with reference to the studies of Ismail et al. (2017), Mathew and Alidmat (2013) as well as Mishra and Yadaz (2004). The items were also checked by two other science teachers. The students rated their response for the survey items on a four-point Likert scale with 1 being 'strongly disagree' and 4 being 'strongly agree'. 
The pre- and post-assessments' results were presented in graphs and analysed statistically using the SPSS. The statistical analysis included one-way ANOVA to examine the significance of the pre- and post-assessments' results between the control and experimental groups, as well as Pearson correlation for the survey data.

\section{RESULTS AND DISCUSSION}

The pre-assessment results of students in the experimental and control groups are shown in Figure 2 in ascending order. Students in both control and experimental groups demonstrated comparable level of understanding of the topic of interest. While few students in the control group generally scored higher in the preassessment, the mark differences are in the range of 1 to 2 which indicate only slight discrepancy in their level of understanding of the topic. This demonstrates that students in both experimental and control groups had evenly distributed academic performance.

\section{Pre-assessment Results of Experimental and Control Groups}

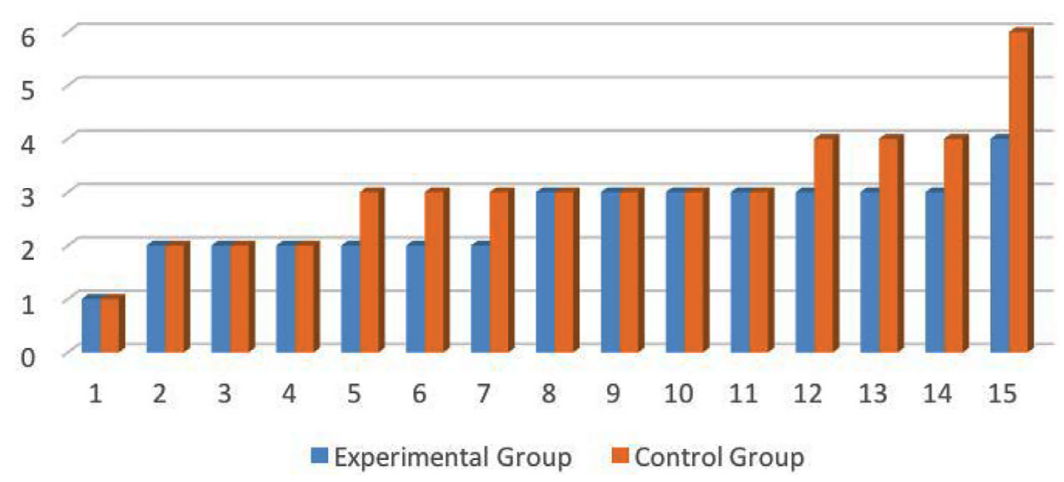

Figure 2. Pre-assessment results of students in the experimental and control groups

The results for pre-assessment and post-assessment of students in the control group showed improved marks, hence level of understanding of the topic in most of the students (refer Figure 3). This indicates that conventional teaching method via diagrams and explanation is able to increase understanding of most students surveyed concerning the topic taught. 


\section{Test Results of Control Group}

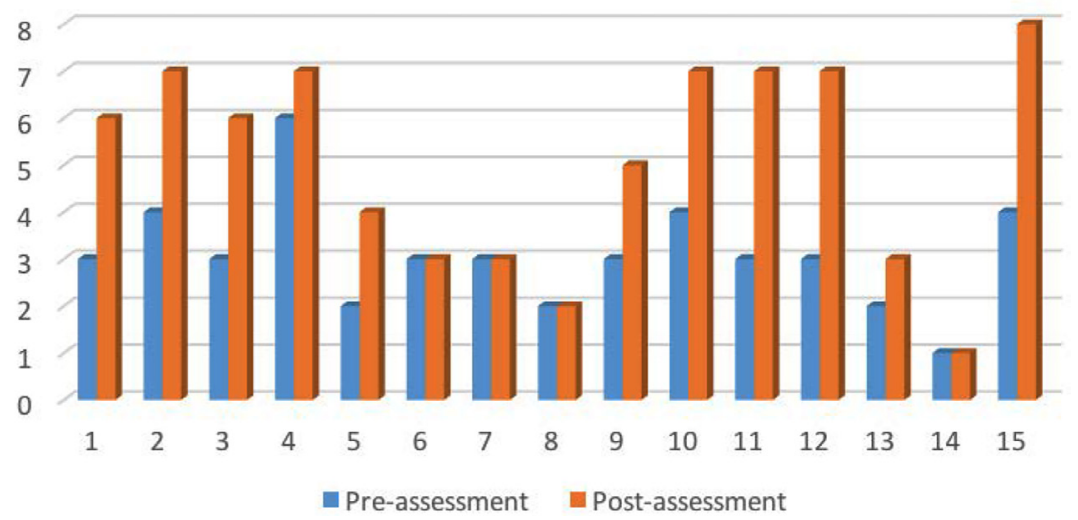

Figure 3. Pre-assessment and post-assessment results of students in the control group

In comparison to the control group, all students in experimental group showed improved grades in post-assessment. The extent of grades improvement is greater in the students of the experimental group than those in the control group (Figure 4). Table 2 shows the mean increase in the marks of the experimental group is 8.5 whereas that of the control group is only 2 . This implies that audiovisual aids significantly increase the level of understanding of students in the topic, leading to higher marks achieved in post-assessment.

\section{Test Results of Experimental Group}

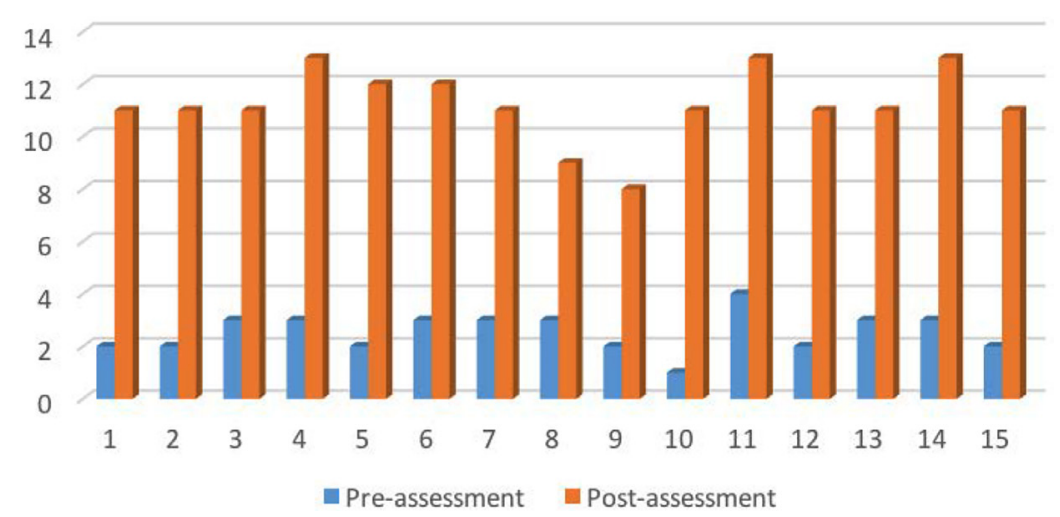

Figure 4. Pre-assessment and post-assessment results of students in the experimental group 
Table 2. Difference in the marks of pre- and post-assessments for each participant

\begin{tabular}{ccccc}
\hline \multicolumn{2}{c}{ Experimental group } & & \multicolumn{2}{c}{ Control group } \\
\cline { 1 - 2 } \cline { 4 - 5 } Student & Mark difference & & Student & Mark difference \\
\hline 1 & +9 & & 1 & +3 \\
2 & +9 & & 2 & +3 \\
3 & +8 & & 3 & +3 \\
4 & +8 & & 4 & +1 \\
5 & +10 & & 5 & +2 \\
6 & +9 & & 6 & 0 \\
7 & +8 & & 7 & 0 \\
8 & +6 & & 8 & 0 \\
9 & +6 & & 9 & +2 \\
10 & +10 & & 10 & +3 \\
11 & +9 & & 11 & +4 \\
12 & +9 & & 12 & +4 \\
13 & +8 & & 13 & +1 \\
14 & +10 & 14 & 0 \\
15 & +9 & 15 & +4 \\
\hline Mean & +8.5 & Mean & +2 \\
\hline
\end{tabular}

The descriptive statistics in Table 3 support the findings above that both groups showed improvement in post-assessment results as indicated by the mean score of 8.133 , in comparison to the pre-assessment mean score of 2.800 . The experimental group achieved significantly higher mean score in the post-assessment $(\mathrm{M}=11.2$, $\mathrm{SD}= \pm 1.373)$ than the control group $(\mathrm{M}=5.067, \mathrm{SD}= \pm 2.219)$. Significance difference in the mean scores of post-assessment between the groups is also captured by ANOVA in Table 4 with $p<0.05(\mathrm{~F}(1,28)=82.86, p=0.000)$. The results are in line with numerous previous studies which reported that incorporation of audio-visual aids in teaching contributed positively to test performance of students (Wong, Ab Jalil, Ayub, Bakar, \& Tang, 2003; De Sousa \& Van Eeden, 2009; Ekinci et al., 2009; Kamaruzaman, Azahari, \& Anwar, 2012; De Sousa et al., 2017; Ismail et al., 2017).

Table 4 also confirms the findings of Figure 1 that academic performance of students in the control group was comparable to those in the experimental group, with $p>0.05(p=0.146)$. This again indicates that the students in both groups were selected to ensure their academic performance, hence cognitive ability was evenly distributed. 
Table 3. Descriptive statistics of assessment results

\begin{tabular}{lccc}
\hline & $\mathrm{N}$ & Mean & Standard deviation \\
\hline Pre-assessment & & & \\
$\quad$ Control group & 15 & 3.067 & 1.1629 \\
$\quad$ Experimental group & 15 & 2.533 & 0.7432 \\
$\quad$ Total & 30 & 2.800 & 0.9966 \\
Post-assessment & & & \\
Control group & 15 & 5.067 & 2.2190 \\
Experimental group & 15 & 11.200 & 1.3732 \\
Total & 30 & 8.133 & 3.6078 \\
\hline
\end{tabular}

Table 4. ANOVA of pre- and post-assessment results

\begin{tabular}{lccccc}
\hline & Sum of squares & df & Mean square & F & Significance, $p$ \\
\hline Pre-assessment & & & & & \\
Between groups & 2.133 & 1 & 2.133 & 2.240 & 0.146 \\
Within groups & 26.667 & 28 & 0.952 & & \\
Total & 28.800 & & & & \\
Post-assessment & & & & & \\
Between groups & 282.133 & 1 & 282.133 & 82.864 & 0.000 \\
Within groups & 95.333 & 28 & 3.405 & & \\
Total & 377.467 & 29 & & & \\
\hline
\end{tabular}

Students in the experimental group were given a simple survey to gauge their perception towards the use of audio-visual aids in the teaching of lower secondary science topics. The results of the survey are shown in Table 5. The survey shows that majority of the students in the experimental group agreed that audio-visual aids motivate them and increase their interest in the learning of science. Majority of the students also found that audio-visual aids help them to remember the contents taught longer and facilitate their understanding and learning of the topic of interest. In general, the students prefer that their teachers incorporate audio-visual aids in teaching and learning.

Pearson correlations (Table 6) showed that most of the survey items are correlated, except a lack of significant correlations between Item 2 with Items 3, 4 and 5. This indicates that students who found audio-visual aids motivated their learning of science also agreed that the aids increased their interest in learning, helped them to remember the contents taught, facilitated their learning of the topic on reproduction and enhanced their understanding of the lessons. Mathew and Alidmat (2013) reported that most undergraduate students surveyed found audio-visual aids useful 
and helped increase retention, which supports the survey findings in this study that students generally agreed on the usefulness of audio-visual aids in facilitating learning, remembering and understanding.

Table 5. Survey of students' perception towards audio-visual aids

\begin{tabular}{llcc}
\hline & Survey item & $\mathrm{n}$ & Mean rating \\
\hline 1 & Audio-visual aids motivate me to learn science. & 15 & 3.43 \\
2 & Audio-visual aids increase my interest to learn science. & 15 & 3.47 \\
3 & $\begin{array}{l}\text { Audio-visual aids help me to remember the contents taught longer } \\
4\end{array}$ & 15 & 3.33 \\
& $\begin{array}{l}\text { Audio-visual aids used facilitate my learning of the topic on } \\
\text { reproduction. }\end{array}$ & 15 & 3.17 \\
5 & $\begin{array}{l}\text { Audio-visual aids facilitate my understanding of the lessons } \\
\text { delivered by my teacher. }\end{array}$ & 15 & 3.47 \\
6 & $\begin{array}{l}\text { I will be more motivated to learn if my teacher incorporates audio- } \\
\text { visual aids in teaching. }\end{array}$ & 15 & 3.63 \\
\hline
\end{tabular}

Table 6. Pearson correlations of survey items

\begin{tabular}{lllllll}
\hline & Item 1 & Item 2 & Item 3 & Item 4 & Item 5 & Item 6 \\
\hline Item 1 & 1 & $0.778^{*}$ & $0.654^{*}$ & $0.813^{*}$ & $0.726^{*}$ & $0.922^{*}$ \\
Item 2 & $0.778^{*}$ & 1 & 0.421 & 0.442 & 0.487 & $0.577^{*}$ \\
Item 3 & $0.654^{*}$ & 0.421 & 1 & $0.598^{*}$ & $0.615^{*}$ & $0.733^{*}$ \\
Item 4 & $0.813^{*}$ & 0.442 & $0.598^{*}$ & 1 & $0.892^{*}$ & $0.664^{*}$ \\
Item 5 & $0.726^{*}$ & 0.487 & $0.615^{*}$ & $0.892^{*}$ & 1 & $0.869^{*}$ \\
Item 6 & $0.922^{*}$ & $0.577^{*}$ & $0.733^{*}$ & $0.664^{*}$ & $0.869^{*}$ & 1 \\
\hline
\end{tabular}

* Significant correlation at the 0.01 level (1-tailed)

Ismail et al. (2017) highlighted the ability of multimedia elements to enhance imagination and visualisation. This might have contributed to increased retention of information, hence learning of reproduction-themed lesson which was difficult to imagine without audio-visual elements (Akram et al., 2012). Audio-visual aids provide auditory and visual stimuli which facilitate registration of information in the short-term memory (Mayer, 2001). Consolidation of the verbal and pictorial models in the short-term memory with prior knowledge in the long-term memory (Mayer, 2001) might contribute to longer retention of contents taught as expressed by the survey respondents. The overall experience of the students with audiovisual aids resulted in their receptivity towards incorporation of audio-visual aids in teaching (Item 6, Table 5 and Table 6). 
It is noteworthy that the students' interest to learn were, to a lesser extent, affected by the ease of remembering the contents taught longer, as well as facilitation in learning and understanding a topic of interest. It is well-accepted that motivation stirs the learning interest of students, as also shown in the correlation analysis (Table 6) (Ismail et al., 2017; Cheung, 2017) but interest itself is an intrinsic factor governed by a set of other more prevailing influences for instance situational interest in science lessons, individual interest in science and science self-concept (Cheung, 2017). While situational interests can be aroused via audio-visual aids, the other two factors affecting interest, hence motivation require more elaborate strategies.

Classroom observation revealed that students in the experimental group were more focused and attentive compared to students in the control group, particularly when the audio-visual aids were played. This is probably because the audio-visual aids managed to draw their attention, which is consistent with higher retention among students reported by Mathew and Alidmat (2013). Students in the experimental group were more able to answer questions asked by the teacher and seemed to develop a better picture of the contents delivered.

The authors find that use of audio-visual aids in rural school faces many limitations. Not all classrooms in rural secondary schools are equipped with LCD projectors and computers to enable display of audio-visual aids. Therefore, teachers often have to either bring projectors and laptops to class or mobilize students to classrooms with multimedia facilities to enable the use of audio-visual aids. Besides, the rural secondary school where the study was conducted did not have stable internet connection and it was not possible to directly access video-sharing websites to play video on the spot during teaching. Teachers often had to download the audio-visual aids beforehand to ensure unobstructed playback. Awasthi (2014) pointed out that attitude of teachers and school management as well lack of fund are among the common obstacles in the use of audio-visual aids for teaching. Similarly, this study unveiled insufficient resources and internet connectivity which lead to elaborate measures for teachers to use audio-visual aids, thus negatively impacting their attitude and intention towards the use of such aids.

Therefore, to enable effective use of audio-visual aids in rural secondary schools, teachers could download the suitable audio-visual aids beforehand and get the help of other teachers teaching the same subject to review the aids to ensure their suitability. Collection of suitable audio-visual aids can be a collaborative effort and securing portable LCD projectors and laptops is crucial. Budget allocation for such purpose should be looked into (Awasthi, 2014; Capper, 2003). 
Nonetheless, there are few limitations in relation to this study. This study only investigates the effectiveness of audio-visual aids in the delivery of lower secondary science topic on reproduction in a rural secondary school. Confirmatory studies can be conducted in other secondary schools on the same topic. Besides, effectiveness of audio-visual aids in the teaching of other topics and other subjects can be investigated. It is also of interest to investigate the characteristics of audiovisual aids that are effective to increase understanding of students, hence the grades achieved.

\section{CONCLUSION}

The study shows that audio-visual aids are effective in increasing the understanding of students in a rural school in Miri on the topic of reproduction, as indicated in the improved marks acquired in post-assessment. Students were observed to be more attentive when audio-visual aids were played. Majority of students agreed that the use of audio-visual aids increase their interest to learn as well as ability to learn and remember the contents. It is suggested that teachers in rural secondary schools could download the audio-visual aids prior to using them in lesson delivery and the aids should undergo review to ensure appropriateness. In rural schools, allocation and maintenance of portable hardware for display of the audio-visual aids in teaching and learning should be looked into. By and large, the findings shed empirical insight into the effectiveness of audio-visual aids in the teaching of lower secondary science in rural setting. The specific obstacles to effectively utilizing audio-visual aids have been identified. The study has also proposed suggestions to streamline the use of audio-visual aids in rural schools in order that the teaching and learning quality gap between urban and rural schools in Malaysia can be narrowed or filled in completely.

\section{REFERENCES}

Aggarwal, J. C. (2009). Principles, methods \& techniques of teaching. India: Vikas Publishing House Pvt. Ltd.

Akram, S., Sufiana, \& Malik, K. (2012). Use of audio visual aids for effective teaching of biology at secondary schools level. Education Leadership, 50, 10597-10605.

Ashaver, D., \& Igyuve, M. S. (2013). The use of audio-visual materials in teaching and learning process in College of Education Benue state, Nigeria. Journal of Research and Method of Education, 6(1), 44-55.

Awasthi, D. (2014). Utilising audio visual aids to make learning easy and effective in primary education. International Journal of Scientific Research, 3, 62-68. https://doi.org/10.15373/22778179/August2014/21 
Capper, J. (2003). Complexities and challenges of integrating technology in the curriculum. TechKnowLogia, 5(1), 60-63.

Cheung, D. (2017). The key factors affecting students' individual interest in school science lessons. International Journal of Science Education, 40(1), 1-23. https://doi.org/ 10.1080/09500693.2017.1362711

De Sousa, L. O., \& Van Eeden, E. S. (2009). Clear-cut to high-tech: History teaching and learning support material (TLSM) drawing on information and communication technology (ICT). Yesterday and Today, 4, 17-40.

De Sousa, L. O., Richter, B., \& Nel, C. (2017). The effect of multimedia use on the teaching and learning of Social Sciences at tertiary level: a case study. Yesterday and Today, 17, 1-22. https://doi.org/10.17159/2223-0386/2017/n17a1

DeBernardes, A., \& Olsen, E. G. (1948). Audio-visual and community materials: Some recent publications. Education Leadership, 256-266.

Ekinci, D., Karakoç, E., Hut, D., \& Avci, H. E. (2009). Using multimedia technologies as a current trends on social sciences education. International Sustainable Symposium on Development Proceedings, Additional volume, 93-106.

Gilakjani, A. P. (2012). The significant role of multimedia in motivating EFL learners' interest in English language learning. International Journal of Modern Education and Computer Science, 4(4), 57-66.

Haque, M. S., \& Talukder, M. H. K. (2017). Audio visual aids-quality use in lecture classes of undergraduate medical education in Bangladesh. Medicine Today, 28(2), 4851. https://doi.org/10.3329/medtoday.v28i2.32923

Ismail, M. E., Othman, H., Amiruddin, M. H., \& Ariffin, A. (2017, May). The use of animation video in teaching to enhance the imagination and visualization of student in engineering drawing. IOP Conference Series: Materials Science and Engineering, 203(2), 12-23.

Jarosievitz, B. (2011). ICT, Multimedia used in the national and international educational projects. Informatika, 38, 22.

Jarosievitz, B. (2015). The impact of ICT and multimedia used to flip the classroom (Physics lectures) via smart phones and tablets. In L. J. Thomas, R. Girwidz (Eds.), Proceedings of the 20th International Conference on Multimedia in Physics Teaching and Learning (pp. 357-363). Germany: LMU Munich.

Kamaruzaman, M. F., Azahari, M. H., \& Anwar, R. (2012). Role of video application as an instructional strategy for students learning development. In Humanities, Science and Engineering Research (SHUSER), 2012 IEEE Symposium (pp. 1351-1354). IEEE. https://doi.org/10.1109/SHUSER.2012.6268817

Keene, M. D. (2006). Viewing video and DVD in the EFL classroom. Bunkyo Gakuin University Journal, 8(1), 217-234.

Khan, N., Shah, K., Farid, N., \& Shah, S. (2016). Perception of high schools principals about the weak English speaking skill of teachers in District Peshawar. Asian Journal of Social Sciences \& Humanities, 5(2), 29-36.

Lee, Y., \& Keckley, K. (2006). Effects of a teacher-made multimedia program on teaching driver education. Teaching Exceptional Children Plus, 2(5) Article 5. Retrieved 20 December 2017 from http://escholarship.bc.edu/education/tecplus/vol2/iss5/ art5 
Malik, S., \& Agarwal, A. (2012). Use of multimedia as a new educational technology tool: A study. International Journal of Information and Education Technology, 2(5), 468-471. https://doi.org/10.7763/IJIET.2012.V2.181

Mathew, N. G., \& Alidmat, A. O. H. (2013). A study of the usefulness of audiovisual aids in EFL classroom: implications for effective instruction. International Journal of Higher Education, 2(2), 86-92. https://doi.org/10.5430/ijhe.v2n2p86

Mayer, R. E. (2001). Multimedia learning. Cambridge: Cambridge University Press. https://doi.org/10.1017/CBO9781139164603

Mayer, R. E. (2002). Cognitive theory and the design of multimedia instruction: An example of the two-way street between cognition and instruction. New directions for teaching and learning, 2002(89), 55-71. https://doi.org/10.1002/tl.47

Mishra, S. K., \& Yadav, B. (2004). Audio-Visual Aids \& The Secondary School Teaching. Global Journal of Human-Social Science, 15, 72-94.

Oyesola, G. O. (2014). Criteria for selecting audio-visual material in Geography in post primary institution. Retrieved from www.unilorin.edu.ng.

Pandian, A., \& Baboo, S. B. (2011). Transforming literacy in Malaysian schools: Teachers, changes \& the agenda on learning by design. International Journal of Learning, $17(11), 63-86$.

Ranasinghe, A. I., \& Leisher, D. (2009). The benefit of integrating technology into the classroom. International Mathematical Forum, 4(40), 1955-1961.

Rao, T. S., \& Jyoti, A. A. V. (2012). Utilisation of audio-visual aids at Government Primary School in Vishakhapattnan District, Andhra Pradesh. International Journal of Multidisciplinary Educational Research, 1(2), 311-318.

Shah, I., \& Khan, M. (2015). Impact of multimedia-aided teaching on students' academic achievement and attitude at elementary level. US-China Education Review A, 5(5), 349-360.

Wong, S. L., Ab Jalil, H., Ayub, A. F. M., Bakar, K. A., \& Tang, S. H. (2003). Teaching a discrete information technology course in a constructivist learning environment: is it effective for Malaysian pre-service teachers? The Internet and Higher Education, 6(2), 193-204. https://doi.org/10.1016/S1096-7516(03)00025-3

Zheng, B., Warschauer, M., Lin, C. H., \& Chang, C. (2016). Learning in one-to-one laptop environments: A meta-analysis and research synthesis. Review of Educational Research, 86(4), 1052-1084. https://doi.org/10.3102/0034654316628645 